\title{
The Role of Technology in Adapting to the New Normal of Medical Education for South East Asian Region
}

\author{
Karunathilake, I.M.
}

\begin{abstract}
COVID-19 has inflicted an unexpected and unprecedented degree of uncertainty worldwide. Medical Education in the South East Asian (SEA) region is not an exception. Experts predict that life would not be the same as in the pre-COVID era. The 'new normal' has become a buzzword.
\end{abstract}

In the wake of the COVID-19 pandemic, Medical Education worldwide has seen some remarkable changes. The digital and technological transformation of Medical Education has accelerated due to the challenges of adapting to the post COVID new normal (Rose et al., 2020)

However, there are many unique challenges faced by Medical Educators in the SEA region. This has been further complicated by the different stages of pandemic observed between countries in the region (Sahi et al., 2020).

One of the main challenges experienced by most universities in SEA region is the constraints on acquisition of hardware, training human resources, availability of low cost/free software solutions coupled with financial difficulties. Use of technology should be aligned with the educational needs and requirements of its users. Developing soft skills such as ethics, cognitive skills and empathy, which is essential for medical doctors requires innovative approaches (Karunathilake, 2017; Tenzin et al., 2020).

The pandemic has brought to the fore the importance of institutional readiness in facing the challenge of adapting to the new normal.

Professor Indika Karunathillake

Head, Department of Medical Education,

Head, WHO Collaborating Centre for Medical Education,

Faculty of Medicine, University of Colombo, Sri Lanka.

Email:karunathilake@hotmail.com
This adaptation requires several transformations such as in financial, infrastructure, hardware and resource management, etc. This should be achieved by implementing a well thought through plan to utilize the existing available resources. Digitalization of medical education requires a total paradigm shift of teaching (Sahi et al., 2020).

The need of adapting to the new normal has accelerated the digital transformation of Medical Education. Simulation-based education and virtual reality have now become integral components of the field and with creativity and imagination, the sky is the only limit. In an era of technology, it is important to make the best use of the technology and take the new normal as a blessing in disguise. If you look in the right places, tomorrow's technology is already there.

\section{References}

Karunathilake, I.M. (2017) Technology Enhanced Learning with Limited Resources-Transforming Limitations into Advantages. South-East Asian Journal of Medical Education, 11, 1.

Rose, S. (2020) Medical student education in the time of COVID-19. Jama, 323, 21, pp. 21312132.

Sahi, P.K., Mishra, D. \& Singh, T. (2020) Medical Education amid the COVID-19 Pandemic. Indian Pediatrics. [E-pub ahead of print] Available at https://www.indianpediatrics.net/COVID29.03.20 20/SA-00181.pdf.

Tenzin, K., Karunatilaka, I.M., Rimal, J., Wangdi, P., Gyamtsho, S., Tobgay, T., Dorji, G., Pradhan, D., Tshering, D., Supe, A., Jayasinghe, S., Siebeck, M. \& Tenzin, T. (2020) The Making of 21st Century Doctors of Bhutan; Use of Artificial Intelligence, Big Data and Values Appropriate for the New Normal in the 21st Century. South-East Asian Journal of Medical Education, 14, 1. 